Avrupa Bilim ve Teknoloji Dergisi

Özel Sayı 26, S. 369-373, Temmuz 2021

(C) Telif hakkı EJOSAT'a aittir

Araștırma Makalesi
European Journal of Science and Technology

Special Issue 26, pp. 369-373, July 2021

Copyright C 2021 EJOSAT

Research Article

\title{
Web Tabanlı Tez Yönetim Sistemi
}

\author{
Yasin Badur ${ }^{1 *}$, Dursun Akaslan ${ }^{2}$ \\ 1* Harran Üniversitesi, Mühendislik Fakültesi, Bilgisayar Mühendisliği Bölümü, Şanlıurfa, Türkiye (ORCID: 0000-0002-7126-6426), yasin.badur.nk@gmail.com \\ ${ }^{2}$ Harran Üniversitesi, Mühendislik Fakültesi, Bilgisayar Mühendisliği Bölümü, Şanlıurfa, Türkiye (ORCID: 0000-0003-3432-8154), dursunakaslan@ harran.edu.tr
}

(3rd International Congress on Human-Computer Interaction, Optimization and Robotic Applications June 11-13, 2021)

(DOI: $10.31590 /$ ejosat.944268)

ATIF/REFERENCE: Badur, Y. \& Akaslan, D. (2021). Web Tabanlı Tez Yönetim Sistemi. Avrupa Bilim ve Teknoloji Dergisi, (26), 369-373.

$\ddot{O} \mathbf{z}$

Tez üniversitelerde ve yüksekokullarda öğrenciler veya öğretim üyeleri tarafından belli bir konu hakkında yaptıkları araştırmaları, belli kurallar çerçevesinde hazırlayıp, genellikle bir sınav kurulu önünde savundukları bilimsel eser olarak tanımlanmaktadır. Tezler, bilimsel çalışma ve araştırmaların önemli bir kısmını oluşturmaktadır. Tez çalışması üzerinde yoğun emek sarf edilmektedir. Yapılan bilimsel çalışmanın rapor haline getirilmesi belli şablonlara göre yapılmaktadır. Bu çalışmanın amacı tez yazımını kolaylaştırmak, tez çalışması sürecini elektronik ortama taşımak, tez yazarının tezin biçimi üzerinde harcadığı zaman kaybını önlemek, intihal kontrollerini sağlamak, enstitülerin tezlerin biçim açısından kontrolleri için harcadığı zaman kaybını önlemek ve benzeri birçok çalışma için Web Tabanlı Tez Yönetim Sistemi tasarlanıp geliştirilmiş̧ir. Sistem en yaygın PHP uygulama çatılarında biri olan Codeigniter'in dördüncü sürümü, PHP programlama dili, MySQL Server veri tabanı, HTML, CSS ve JavaScript kullanılarak geliştirilmiştir. Sistem, toplam 49 veri tabanı tablosu olmak üzere 4 farklı rol altında 11 modülden oluşmaktadır. Veri tabanı ve sistem tasarımından önce 40 tane enstitünün Tez Yazım Şablonu ve Kılavuzları incelenmiştir. Böylece tezin tüm süreçlerinin elektronik ortama geçirmeden önce gerekli bilgiler toplanarak sistem tasarlanmıştır. Geliştirilen bu sistem öğrencilerin tez yazım ve yönetim sürecini hem danışmanların hem de enstitü yönetimi tarafından anlık olarak takip edilebilmesini; ayrıca danışmanlar tarafından öğrencilerinin günlük performslarını izleyebilme ve anlık olarak tez içeriğini değerlendirilebilmelerini olanak sağlamaktadır. Bu sistem tez yazımı ve yönetimi sürecine önemli katkılar sunmaktadır. Ayrıca enstitülerin tezlerin yönetimi ve kontrolleri konusunda önemli katkılar sunmaktadır.

Anahtar Kelimeler: Tez yazımı, Tez yönetimi, Tez şablonu, Elektronik tez sistemi, Web tabanlı tez.

\section{Web Based Thesis Management System}

\begin{abstract}
Thesis is defined as a scientific work that students or faculty members in universities and colleges prepare on a certain subject within the framework of certain rules and defend them in front of an examination board. Theses constitute an important part of scientific studies and researches. A lot of effort is spent on the thesis work. The reporting of the scientific study is done according to certain templates. The aim of this study is to facilitate the writing of the thesis, to transfer the thesis work process to the electronic environment, to prevent the loss of time spent by the thesis author on the format of the thesis, to ensure plagiarism checks, to prevent the loss of time spent by the institutes for checking the theses in terms of format, and many similar studies have been designed and developed Web Based Thesis Management System. The system was developed using the fourth version of Codeigniter, one of the most common PHP application frameworks, PHP programming language, MySQL Server database, HTML, CSS and JavaScript. The system consists of 11 modules under 4 different roles, with a total of 49 database tables. Before the database and system design, Thesis Writing Templates and Guides of 40 institutes were examined. Thus, the system was designed by collecting the necessary information before transferring all the processes of the thesis to the electronic environment. This developed system allows the students to follow the thesis writing and management process instantly by both the advisors and the institute management; It also allows the advisors to monitor the daily performances of their students and to evaluate the thesis content instantly. This system makes significant contributions to the thesis writing and management process. It also provides important contributions to the management and control of the theses of the institutes.
\end{abstract}

Keywords: Thesis writing, Thesis management, Thesis template, Electronic thesis system, Web-based thesis.

*Sorumlu Yazar: yasin.badur.nk@gmail.com 


\section{Giriş}

Tez üniversitelerde ve yüksekokullarda öğrenciler veya öğretim üyeleri tarafından belli bir konu hakkında yaptıkları araştırmaları belli kurallar çerçevesinde hazırlayıp genellikle bir sınav kurulu önünde savundukları bilimsel eser olarak tanımlanan en uzun akademik yazım türlerinden biridir (TDK, 2021). Tezler ön lisans, lisans, yüksek lisans ve doktora eğitimlerini bitirme sürecinde üzerinde yoğun bir emek sarf edilerek üretilen bilimsel çalışmalardır. Bu eğitimleri bitirmenin şartı ve eğitim sürecini tamamlamanın önemli bir öğesidir. Tez çalışması yapılırken kabul edilmiş bilimsel kurallara uyulması ve üniversite tarafından belirlenen esaslara göre yazılması zorunlu olup, tezin rapor haline getirilme sürecine yardımcı olması için tez rapor formatına ilişkin kılavuzlar ilgili birimler tarafından hazırlamakta ve yayımlanmaktadır (Bahşişoğlu, 2001). Bu kılavuzlar tez yazarının tezi nasıl yazması gerektiği hakkında detaylı bilgiler vermektedir. Ancak bu kılavuzlardaki bilgilere göre web tabanlı çalışan ve sistem üzerinde tanımlanmış şablona göre bir çıktı verebilecek bir web uygulamasına rastlanılmamıştır.

Tonta ve diğerleri (2006) "Hacettepe Üniversitesi Elektronik Tez Projesi" adlı çalışmalarında yüksek lisans, doktora ve sanatta yeterlik tezlerinin tam metinlerinin internet aracılığıyla herkesin erişimine açmışlardır. Hacettepe Üniversitesi Kütüphanesinden sağlanan 50 basılı tez taranmış, tezlerin tam metinleri Dublin Core standardına göre hazırlanmış, dizin bilgileriyle birlikte dijital ortama aktarılmıştır. Tezlerin elektronik ortama taşınması için ilk adım olarak nitelendirmektedir (Tonta ve diğerleri, 2006). Dolayısıyla bu proje aslında hedeflenen Web Tabanlı Tez Yönetim Sistemine ilk adım olarak nitelendirilebilir.

Günümüzde internet ortamında bilgi paylaşımı ve bilgiye erişim giderek çoğalmaktadır. Aynı zamanda internet üzerinden çeşitli uygulamalar ile yapılan iş ve işlemlerde artmaktadır (Tonta ve diğerleri, 2006). Bu değişim ve gelişim tez çalışmalarının internet ortamında yapılması gerektiğini ortaya koymaktadır. Günümüzde çoğu enstitünün tez yazım şablonu bulunmaktadır. Enstitüler bu dokümanları kendi resmî web sayfaları üzerinden yayımlamaktadır. Bazı enstitüler şablonlarında kapak, özet gibi ortak bölümleri öğrencilerin kolayca doldurabilmesini sağlayacak, çoktan seçmeli menüler ile bir kelime işlemci programı kullanmışlardır. Diğer taraftan Yüksek Öğretime Kurulu'na (YÖK) bağlı üniversitelerimizde web ortamında tez yazmanın tüm süreçlerini kapsayan ve bu tezlerin içeriklerini yönetebilen web tabanlı bir sistem kullanan enstitüye rastlanılmamıştır.

Dolayısıyla lisans, yüksek lisans ve doktora öğrencilerinin tezlerinin çevrim-içi ortamda yazabilmeleri için içerik yönetim sistemlerinde olduğu gibi tez yazım ve yönetim sürecinin her aşamasında öğrencilere yardımcı olacak web tabanlı çalışan bir sisteme ihtiyaç duyulmaktadır. Çevrim-içi ortamda tezlerin yazılabilmesi ve yönetilebilmesini sağlayacak bir sistem ile öğrenci tez yazım sürecinin danışmanlar tarafından anlık olarak izlenmesinin sağlanması, intihallerin önüne geçilmesi, yazım hatalarının önlenmesi ve benzeri birçok katkı sunacaktır. $\mathrm{Bu}$ çalışmanın amacı tez yazım sürecinin tamamını kapsayan ve bahsedilen katkıları sunmay hedefleyerek web tabanlı uygulamanın tasarlanıp ve geliştirilmesi olarak belirlenmiştir. Uygulama, açık kaynak kodlu PHP programla dili, bu dil ile yazılmış web çatısı olan Codeigniter'in dördüncü sürümü,
JavaScript, CSS, HTML ve veri tabanı yönetim sistemi MySQL kullanılarak geliştirilmiştir. Uygulamanın testleri proje ve tez yazan öğrenciler tarafından yapılarak; eksiklerin giderilmesi ve daha işlevsel bir sistemin ortaya çıkarılması hedeflenmiştir. Nihai hedef olarak tüm üniversitelerin bulut bilişim teknolojileri ile böyle bir sistemin hayata geçirilmesine ön ayak olabilmek ve bu alanda yapılacak çalışmalara katkı sağlamaktır.

\section{2. Önceki Çalışmalar}

YÖK Tez Merkezi istatistiklerine göre günümüze doğru yazılan tez sayılarının katlanarak artış gösterdiği görülmüştür (YÖK Tez Merkezi İstatistikler, 2021). Tez çalışmalarının artması ile birlikte tez yazım sürecinde karşılaşılan zorluklarda irdelenmeye başlanmıştır. Tez çalışmasını yapanların karşılaştıkları zorluklar sorulduğunda; tez yazım sürecinde farklı kısımlarda zorluklarla karşılaştıklarını, ancak en çok bilmedikleri bir analizi yapma ve akademik yazma konularında zorlandıklarını belirtmişlerdir (Yıldırım \& Onaylı, 2016). Yıldırım ve Onaylı (2016) çalışmalarındaki tespit ettikleri akademik yazma ile ilgili zorlukları çözebilmek için web tabanlı çalışan bir uygulamanın gerekliliğini ortaya koymaktadır.

Yapılan literatür taramasında web ortamında tez yazmanın tüm süreçlerini kapsayan ve bu tezlerin içeriklerini yönetebilen komple web tabanlı bir sisteme rastlanılmamıştır. YÖK'ün resmi tez veri tabanı olan YÖK Ulusal Tez Merkezi (https://tez.yok.gov.tr) uygulaması bulunmaktadır. Web üzerinden çalışan bu uygulama ile tezler dijital ortama taşınmış olup, sistem üzerinden tez kabulü yapılabilmektedir. Yine sistem üzerinden tezlerin kolayca taranabilmesi ve dijital bir ortama kaydedilebilmesi sağlanmıştır. Benzer bir sistem olan M. Akçay ve Hüseyin Karakullukçu (2016) “Tez Kayıt Sistemi” adlı tam metin bildiride üniversitelerin ihtiyaç duyacağı, öğrencilerin tezlerini sisteme yükleyip diğer öğrencilerin de bu tezler üzerinde araştırma yaparak kendi çalışmalarına katkı sağlayacakları bir sistem geliştirilmiştir (Akçay \& Karakullukçu, 2016). Ancak bu iki çalışmada da tez yazımının tüm süreçlerini kapsamadığından, bu yönüyle geliştirilen Web Tabanlı Tez Yönetim Sisteminden ayrılmaktadır. Web Tabanlı Tez Yönetim Sistemi bu işlevleri içerecek şekilde tasarlanmıştır.

Por ve diğerleri (2012) yaptıkları "A Grid Enabled E-Theses and Dissertations Repository System" adlı çalışmalarında manuel tez, hibrit elektronik tez ve elektronik tez sistemlerini karşılaştırarak, bu sistemlerdeki eksiklerin giderilebileceği bir sistem önermişlerdir. Önerilen bu sistem YÖK Ulusal Tez Merkezine benzer bir işlevselliğe sahiptir. Çalışma ile daha büyük veriler üzerinde tez taramasının hızlandırılması ve daha büyük dosya işlemleri için öneriler sunulmuştur. Web Tabanlı Tez Yönetim Sisteminin uzun bir süre kullanıldıktan sonra tez tarama ve dosya işlemleri için çalışmada bahsedilen öneriler doğrultusunda iyileştirmeler yapılmasına katkılar sunacaktır.

Çiftçi (2018) Çoklu Elektronik Dergi Yönetim Sistemi (ÇEDYS) adlı yüksek lisans tez çalışmasında ulusal ve uluslararası hakemli bilimsel dergiler için gönderilen makalelerin kayıt, kabul, editör ve hakem değerlendirme süreçlerinin çevrimiçi olarak yürütülebilmesini ve sonuçlandırılmasını sağlayan bir yazılım geliştirilmiştir (Çiftçi, 2018). Yazılımın geliştirilmesinde kullanılan teknolojiler ve veri tabanı detaylı olarak açıklanmıştır. Bu yönüyle Web Tabanlı Tez Yönetim Sisteminin geliştirilmesinde kullanılan teknolojilerin seçimi aşamasında katkı sağlayan bir çalışma olmuştur. "Bilimsel Dergiler için Bir İçerik Yönetim Sistemi Tasarımı ve 
Uygulaması" (Doğan \& Şen, 2007) adlı makale ile bilimsel dergiler için etkileşimli güncelleme yapabilen bir içerik yönetim sisteminin tasarımı ve uygulamasını gerçekleştirebilen ÇEDYS'ye benzer bir sistem olduğu görülmektedir. Ancak çalışmada tez yazımının yapılabildiğinden bahsedilmemiştir.

\section{Web Tabanlı Tez Yönetim Sistemi}

Web Tabanlı Tez Yönetim Sisteminin geliştirilmesinde Veri Tabanı Yönetim Sistemi olarak MySQL Server kullanılmıştır. Sisteminin arka yüz tasarımında PHP programlama dili ve PHP ile geliştirilen web çatısı olan Codeigniter'in dördüncü sürümü kullanılmıştır. Sistemin ön yüz tasarımında HTML, CSS ve JavaScript ile birlikte bunlarla geliştirilmiş olan Bootstrap kullanılmıştır. $\mathrm{Bu}$ teknolojilerin sistem geliştirilmesinde tercih edilmesinin en önemli nedeni açık kaynak kodlu olarak geliştirilmiş olmalarıdır. Geliştirme ortamı olarak sağladığ kolaylıklar ve öğrenci için ücretsiz lisanslama yapmasıdan dolayı PHPStorm tümleşik geliştirme ortamı tercih edilmiştir.

\subsection{Veri Tabanı Tasarımı}

Sistemin veri tabanı tasarımı için öncelikle detaylı bir analiz çalışması yapılmıştır. Bu analiz çalışması kapsamında 96 devlet üniversitesi Fen Bilimleri Enstitüsünün web sayfaları incelenerek 40 tanesinin "Tez Yazım Şablonlarını" incelenmiştir. Ayrıca şablonun yetersiz kaldığı kısımlarda "Tez Yazım Kılavuzuna" başvurulmuştur. Tüm tez sürecini tasarlayabilmek için tez yazım süreci hakkında detaylı bilgiler toplanmıştır. Yapılan analiz çalışması sonuçlarına göre veri tabanı tasarımı gerçekleştirilmiştir. Tasarlanan veri tabanı 49 tane tablodan oluşmaktadır. Tüm tablolar ilişkisel olarak tanımlanıp, veri bütünlüğünü sağlayacak ve veri tekrarını asgariye indirecek şekilde tasarlanmıştır. Veri tabanı tabloları; kullanıcı bilgileri, tez içeriği ve başlıkları, şablon tanım bilgileri, kaynak ve kaynakça stili tanım bilgileri ve üniversite birim bilgileri olmak üzere beş kategoride toplanmıştır. Bu tablolar veri bütünlüğünü sağlayacak uygun ilişkilerle birbirleriyle ilişkilendirilmiştir. Veri tabanı tablolarının, tanımlanan alanların veri türü ise yine incelenen şablonların analiz sonucuna göre belirlenmiştir.

\subsection{Sistem Tasarımı ve Modül İşlevleri}

Web Tabanlı Tez Yönetim Sistemi temelde dört farklı sabit rol ile kullanıcı girişi yapılacak şekilde tasarlanmıştır. Sistem toplam 11 modülden oluşmuştur. Sistemde yer alan modüller rol

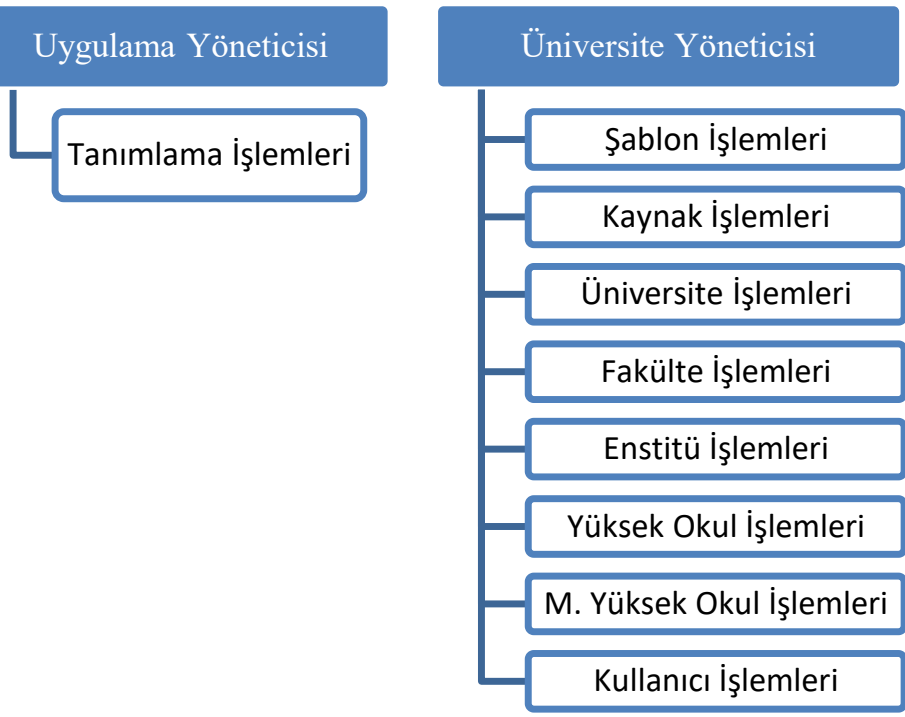

grubuna göre Şekil-1'deki gibi gösterilmiştir.

Sistemin dört sabit rol ile kullanıcı girişi yapılacak şekilde tasarlanmasının amacı; kullanıcıların yapabileceği işlemleri net olarak birbirinden ayırmaktır. Sistem kurulumu sırasında zorunlu olarak Uygulama Yöneticisi rolünde kullanıcı bilgilerinin sisteme tanımlanmasını sağlayacak şekilde tasarlanmıştır. Böylece yönetici hesabı olmaksızın diğer rollere ait kullanıcı hesaplarının oluşturulması engellenmiştir. $\mathrm{Bu}$ dört role sahip kullanıcıların yapabildiği işlemler aşağıdaki gibi açıklanmıştır.

\subsubsection{Uygulama Yöneticisi}

Uygulama Yöneticisi olarak giriş yapan kullanıcı üniversite bilgilerini tanımlama işlemlerini yapabilmektedir. $\mathrm{Bu}$ işlemler kısaca; üniversite hiyerarjisinde yer alabilecek birim adları için birim etiketi tanımlama, yeni üniversite ekleme, üniversiteleri listeleme ve güncelleme, üniversite yöneticisi ekleme ve güncelleme, üniversite yöneticilerini listeleme şeklindedir. Sistem birden çok üniversite tarafından aynı uygulama üzerinden hizmet verecek şekilde tasarlanmıştır. Dolayısıyla Sistem Yönetici rolüne sahip kullanıcı üniversite ve Üniversite Yöneticisi rolüne sahip kullanıcı tanımlanması yapılmasına izin vermektedir.

\subsection{2. Üniversite Yöneticisi}

Üniversite Yönetici olarak giriş yapan kullanıcı Şekil-1 gösterilen birçok işlemi yapabilmektedir. $\mathrm{Bu}$ ișlemlerden "Üniversite İşlemleri”, "Fakülte İşlemleri”, "Enstitü İşlemleri”, "Yüksek Okul İşlemleri" ve "Meslek Yüksek Okul İşlemleri" üniversite hiyerarşine uygun olarak birim tanımlama ve güncelleme işlemleri yapabilmektedir.

“Kullanıı İşlemleri” modülü ile akademisyen ve öğrenci ekleme, pasife çekme ve güncelleme yapılabilmektedir. Ayrıca bu modül ile öğrenci tez bilgilerini tanımlama, güncelleme ve tezin bazı bölümleri ile ilgili işlemler yapılabilmektedir.

"Şablon İşlemleri” modülü ile üniversiteye birinci seviyede bağlı birime göre detaylı olarak tez şablonu tanımlama ve güncelleme işlemleri yapılabilmektedir. Tez şablonu tanımlama ile şablona ait sayfa yapısı, sayfa numaralandırma türü ve sayfa numarasının konumu, sayfa üst bilgisinin görünürlüğü, sayfa numaralandırma başlangıç bölümü ve şablonda yer alacak bölümler ve başlıklar detaylı olarak tanımlanabilmektedir. Şablonda tanımlanan bölümler kendi içinde dinamik olarak
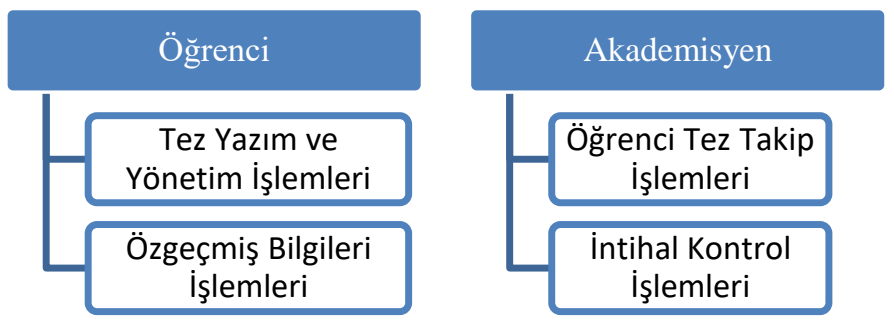
sıralanabilmektedir. Tanımlanmış bir şablonun bölümlerine ait yazı formatı ve büyüklüğü, başlık konumu (sağa, sola veya ortaya yasl1), başlık ve içeriğinin başlama konumu (yeni sayfada veya devam eden sayfada), satır aralığı, satır başı miktarı, alt ve ana başlıklar öncesi ve sonrası boş satır sayısı ve bölüm maksimum sayfa sayısı ve benzeri birçok özellikler detaylı olarak tanımlanmaktadır. Şablonda yer alan "Kapak", "Özet” ve "Onay Sayfası" gibi bölümlerde yer alacak bilgilerde seçimli hale getirilmiştir. Ayrıca bu modül ile tezde yer alan "Etik Bildirim" gibi metinlerde tanımlanabilmektedir. Enstitülerin yayındıkları şablonlar bu modül ile dinamik ve birime göre tanımlama işlemleri sağlanmıştır. Böylece tez yazarı şablonla ilgili işlemlerle kaybedilen zaman engellenmiştir.

“Kaynak İşlemleri” modülü ile öğrencinin tez yazımında yararlandığ 1 kaynaklar ekledikten sonra ilgili birime tanımlanmış kaynakça stiline göre yazılması sağlanmaktadır. Kaynak stili tanımlama işleminde kullanılan kaynaktaki tüm alanların (kitap adı, yayın evi, başlık vb.) ve kaynak türü (kitap, makale vb.) sistem içinde detaylı olarak tanımlanabilmektedir. Tanımlanmış olan kaynak bilgileri ile yeni kaynak türü tanımlanabilip, kaynağa ait bilgileri ve bilgilerin alabileceği değer türleri dinamik olarak atanabilmektedir. Örneğin makale kaynak türünü tanımlamak için önceden tanımlanmış başlık, yazarlar, dergi adı ve benzeri alanlarını dinamik olarak ekleyip, bu alanların alabileceği değer türü (yazı veya numerik), değerin girilmesinin zorunluluk durumu ve alanın açıklaması dinamik olarak tanımlanabilmektedir. Sistemde tanımlanmış her kaynak türünün kaynakça bölümünde nasıl basılacağını dinamik olarak kaynakça stili tanımla işlemi ile yapılabilmektedir. Kaynakça stili tanımla işlemi bu sisteme özgü bir algoritma yazılarak geliştirilmiştir.

\subsection{3. Ö̆̆renci}

Sisteme öğrenci olarak giriş yapan kullanıcı Şekil-1 de görüldüğü üzere iki temel işlem yapabilmektedir. Bunlardan tez işlemleri modülü önemlidir. Tez yazımı ve yönetimi sistemde tanımlanmış şablona göre buradan yapılmaktadır. Öğrencinin tez yazımı ve yönetimi incelenen 40 şablondaki verilere göre modülde üç kısma ayrılmıştır.

İlk kısım “İthaf”, “Proje Destek”, “Önsöz”, “Özet”, "Simgeler", "Kısaltmalar" ve benzeri bölümlerin içeriğinin tanımlandığı kısımdır. Bu kısımda kullanıcı "Simgeler" ve "Kısaltmalar" bölümünde sistemde tanımlı veya yeni kısaltma ve simgeyi tezine ekleyebilmektedir. "Özet" ve "Onay" kısmı bazı verilerin öğrenci tarafından girilerek, bazı verilerinde sistemde tanımlı şablona göre otomatik eklenerek oluşturulmaktadır. Pdf çıktısı alma veya ön izlemede bu bölümler tanımlı şablona göre sistem tarafindan otomatik yapılmaktadır. Yine bu kısımda yer alan dizinler ve içindekiler kısımları sistem tarafından otomatik olarak oluşturulup basılmaktadır.

İkinci kısım, kullanıcı tarafından tez içeriğinin girilmesinin sağlandığı kısımdır. Burada kullanıcı tanımlı şablona göre gelen ana başlıkların altına içerik veya alt başlık ekleyip düzenleyebilmektedir. Tez içeriğinin yazımı zengin metin editörü ile yapılmaktadır. Bu zengin metin editörünün sadece koyu yazı, alt çizgili yazı ve üstel gibi basit fonksiyonları vardır. Çünkü içerik kısmının basımı şablon ile önceden belirlendiğinden kullanıcı tarafından yapılmasına gerek kalmamıştır. Kullanıcı sadece veri girişi yapmakta ve formatı için ayrıca zaman harcamasına gerek kalmamıştır. İçerik ekleme metin, şekil, tablo, resim ve benzeri birçok türlere ayrılarak yapılmaktadır. Örneğin kullanıcı bir resim ekleyecekse, bu türü seçip işleme devam etmektedir. Metin ekleyecekse, metin türü e-ISSN: 2148-2683 seçerek işlem yapabilmektedir. Böylece veriler, türüne göre veri tabanında saklanması sağlanmıştır. Tez içeriğini, türüne göre veri tabanında saklanması ile ham metinleri resim, tablo ve benzeri içerikten ayırarak, tez ana metni üzerinde yapılacak arama ve tarama işlemlerini kolaylaştırmak amacıyla tasarlanmıştır.

Son kısımda kullanıcının yararlandığı kaynaklarını eklediği ve varsa çalışmanın eklerini ekleyebildiği kısımdır. Öğrenci kendisine ait bilgileri özgeçmiş modülü ile detaylı olarak ekleyebilmektedir. Anlaşıldığı üzere sistem üzerinden sadece öğrenciden veri girişi yapılması istenmektedir. Tezin çıktısını alma işlemi tamamen sistemde ilgili birime tanımlı şablona göre yapılmaktadır. Böylece tez yazım ve denetimi kolaylaştırılmıştır.

\subsubsection{Akademisyen}

Akademisyen olarak giriş yapan kullanıcı danışmanlığını yaptığ 1 ögrencilerin tezlerini takip edebilmekte ve başlık veya paragraf bazlı olarak içeriği inceleyip, değerlendirme yapabilmektedir. Yapılan değerlendirmeyi ilgili öğrenci anında görebilmektedir. Ayrıca akademisyen web servislerini kullanarak tez intihal kontrolünü sağlayabilmektedir. İntihal kontrolleri, anlık olarak n-gram algoritması ile internet üzerinden anlık tarama yapılarak yapılması planlanmaktadır.

\section{Tartışma ve Sonuç}

$\mathrm{Bu}$ çalışma sonucunda tez yazım ve yönetim sürecinin tamamının web ortamında yapılmasını sağlayan "Web Tabanlı Tez Yönetim Sistemi” geliştirilmiştir. Bu sistem birden çok üniversite tarafından tek veritabanı üzerinden tez yazım ve yönetim işlemlerine olanak sağlamaktadır. Tez yazımını, ilgili üniversitenin birimine tanımlı şablona göre yapılmasını sağlamaktadır. Öğrenci ve danışman etkileşimini artırmaktadır. Tezlerin web ortamında yönetimini, intihal kontrollerini, taranmasını sağlayarak ayrıca daha birçok özellik ile sürece önemli katkılar sunmaktadır.

$\mathrm{Bu}$ sistem ile öğrencilerin tez yazım ve yönetim süreci hem danışmanları hem de enstitü yönetimi tarafından anlık olarak takip edilebilmektedir. Bu sistem ile danışmanlar öğrencilerinin günlük performslarını izleyebilmekte ve anlık olarak tez içeriğini inceleyip değerlendirilebilmektedir. Yeni koronavirüs hastalığı (COVID-19) ile birlikte danışmaların ve öğrencilerin üniversitelerde fiziksel olarak uzaklaştığı günümüzde, bu sistem sürece önemli bir katkı sağlamıştır. Enstitü yönetimi açısından ise öğrencilerin özlük bilgileri, çalışma istatistikleri, tezlerinde intihal yapıp yapmadıkları ve benzeri bilgiler takip edilebilmektedir. Ek olarak hem öğrenciler için hemde enstitü yönetimi için tezlerin şekil bakımından incelenmesi için harcanan emek ve zaman kaybının önüne geçilmiştir.

Fakat bu sistemin üniversitelere entegre edilebilmesi için üniversitelerin bağlı olduğu mevzuatların güncellenmesi gerekmektedir. Ek olarak enstitüye bağlı anabilim dalları sayısı ve çeşitliliği düşünüldüğünde; tez yazımında kullanılan karakterlerin çeşitliliği, formüller ve benzeri araçların geliştirilen sistemde yeterli değildir. $\mathrm{Bu}$ araçların eksikliği giderilerek sistemin kullanım alanı artırılabilir. Sistem önemli bir kullanıcı kitlesi tarafindan kullanılabilmesi ve kullanımının tavsiye edilmesi halinde özellikleri daha da gelişmiş bir sistemin ortaya çıkmasını sağlayacaktır. 


\section{Kaynakça}

Akçay, M., \& Karakullukçu, H. (2016). Tez Kayıt Sistemi. 4th International Symposium on Innovative Technologies in Engineering and Science, (s. 1055 - 1064). Antalya.

Bahşişoğlu, H. K. (2001). İnternet Kaynakları: Tez Çalışması ve Yazımı. Bilgi Dünyası, 2(2), 256-264.

Baltacı, A. (2020). Araştırmaların Raporlaştırılması: Bir Tez Veya Bilimsel Makale Nasıl Yazılır. Mersin Üniversitesi Sosyal Bilimler Enstitüsü Dergisi, 6 - 39.

Barutçu, F., \& Onayl1, S. (2016). Tez Sürecinde Karşılaşılan Zorluklar. Tez Sürecinde Karşılaşılan Zorluklar (s. 677690). içinde doi:10.14527/9786053183563.042

Çelik, S., \& Buğan, O. (2013). Açık Dergi Sistemleri (ADS) : Açık Kaynak Kodlu Dergi Yönetim ve Yayımlama Sistemi. Yüksekögretim Dergisi, $\quad 3(1), \quad 12-21$. https://kutuphane.dogus.edu.tr/mvt/pdf.php adresinden alind 1

Çiftçi, G. (2018). Çoklu Elektronik Dergi Yönetim Sistemi Geliştirilmesi. Yüksek Lisans Tezi. Afyon.

Demircioğlu, S. (2013). İlişkisel Veri Tabanlarında Anahtar Kelime Arama. Bilişim Teknolojileri Dergisi, 5(3), 51-56. https://dergipark.org.tr/tr/pub/gazibtd/87974 adresinden alınd 1

Deniz, K., \& Karagöl, E. (2017). Akademik Yazma Açısından Tez Yazım Kılavuzları*. Ana Dili Eğitimi Dergisi, 5(2), 287 - 312. doi:https://doi.org/10.16916/aded.298783

Deperlioğlu, Ö., \& Sarpkaya, Y. (2009, Ocak). Öğretim Yönetim Sistemleri İçin Örnek Veri Tabanı Tasarımı. Bilişim Teknolojileri Dergisi, 2(1), 15-21. https://dergipark.org.tr/en/download/article-file/75254 adresinden alınd 1

Doğan, N., \& Şen, Ş. (2007). Bilimsel Dergiler İçin Bir İçerik Yönetim Sistemi Tasarımı Ve Uygulaması. Politeknik Dergisi, 10(4), 53-361.

Eldoğan, D., Korkmaz, L., Helvac1, E., Yeniçeri, Z., \& Kökdemir, D. (2015). Akademik Yazım Kuralları Kitapçı̆̆ (4 b.). Ankara: Eleştirel - Yaratıcı Düşünme Ve Davranış Araştırmaları Laboratuvarı. Ocak 3, 2021 tarihinde http://psk.baskent.edu.tr/docs/AYKK_04.pdf adresinden alındi

Faryadi, Q. (2019). PhD Thesis Writing Process: A Systematic Approach-How to Write Your Methodology, Results and Conclusion. Creative Education, 10, 766-783. doi:10.4236/ce.2019.104057

Firlar, T. (2003, Mart). Uzman Veri-Tabanı Sistemleri Ve Öneriler. SAU Fen Bilimleri Enstitüsü Dergisi, 7(1).

Güncel Türkçe Sözlük. (2021). Türk Dil Kurumu Sözlükleri: https://sozluk.gov.tr/ adresinden alındı

Håkansson, A. (2010). Improving the Thesis Writing Process. FECS 2010 : proceedings of the 2010 international conference on frontiers in education : computer science \& computer engineering (Las Vegas NV, July 12-15, 2010) (s. 389-395). Stockholm: CSREA Press.

Hakkoymaz, V., \& Mollarecep, Ö. (2015). Veri Tabanında Adaptif Yetki Yönetimi ve Uygulaması. Uluslararası Bilgi Güvenliği Mühendisliği Dergisi, 1(2), 1-5.

Müstecaplığlu, M. A. (2017). Akademik Makale Yazımında Sayfa Düzeni Ve Tipografi Seçimi. Sanat-Tasarım Dergisi(8), 29-33. doi:10.17490/Sanat.2018.18

Nadeem, S., \& Guruler, H. (2019). Lisansüstü Tez Yazım Stilini Kolaylaştırmak İçin Editör Yazılımı. Muğla.
Por, L. Y., Ong, S. Y., Beh, D., \& Ismail, M. (2012). A Grid Enabled E-Theses and Dissertations Repository System. The International Arab Journal of Information Technology, 392401.

Sağıroğlu, S., Dener, M., Günes, S., Güllü, A., Tataroğlu, A., Orman, A., . . . Akçay, H. (2015). Ulusal Veritabanı ve Atıf Endeksi Kurulumu için Stratejiler, Problemler ve Çözüm Önerileri. Gazi Üniversitesi Fen Bilimleri Dergisi, 3(2), 01512.

Sanalan, V. A., \& Altun, A. (2002). Electronic Portfolio As A Database Application. Erzincan Üniversitesi Ë̆itim Fakültesi Dergisi, 4(1), 11-21.

Sawaneh, I. A., E. C., Koroma, J. H., Kamara, J. A., Sankoh, I., Sesay, M. S., \& Koroma, A. (2018). Student Dissertation Database Management System: IAMTECH Sierra Leone as a Case Study. International Journal on Data Science and Technology, 4(3), 93-99.

Şencan, H. (1991). Tezin Yapısı. H. ŞENCAN içinde, Tez Yazım Kılavuzu (s. 33-39). İstanbul: İ.Ü İşletme Fakültesi Yayınları.

Tekerek, A., \& Bay, Ö. F. (2009). Web İçerik Yönetim Sistemi Tasarımı ve Gerçekleştirilmesi. Politeknik Dergisi, 12(2), $85-91$.

Tonta, Y., \& Akbulut, M. (2019). Türkiye'de Lisansüstü Tezlere Açık Erişim. Türk Kütüphaneciliği, 33(4), 219 - 248. https://dergipark.org.tr/tr/pub/tk/issue/50920/620508 adresinden alındı

Tonta, Y., Küçük, M. E., Umut Al, G. A., Olcay, N. E., Soydal, İ., \& Ünal, Y. (2006). Hacettepe Üniversitesi Elektronik Tez Projesi Raporu. Ankara: Hacettepe Üniversitesi Bilgi ve Belge Yönetimi Bölümü.

Ulaş, M., \& Boyacı, A. (20). Hiyerarşik Bir İçerik Yönetim Sistemi Geliştirilmesi. Engineering Sciences, 7(1), 1-13. 2021 tarihinde https://dergipark.org.tr/tr/pub/nwsaeng/issue/19855/212629 adresinden alındı

Uzun, E., Buluş, H. N., \& Erdoğan, C. (2018). Veritabanı Tasarımının Yazılım Performansına Etkisi: Normalizasyona karşı Denormalizasyon. Fen Bilimleri Enstitüsü Dergisi, 22(2), 887-895.

Yıldırım, F. B., \& Onaylı, S. (2016). Tez Sürecinde Karşılaşılan Zorluklar. Pegem Atıf Indeksi, 677-690.

YÖK Tez Merkezi Istatistikler. (2021). YÖK Tez Merkezi: https://tez.yok.gov.tr/UlusalTezMerkezi/IstatistikiBilgiler?isl em $=3$ adresinden alındı. 